\title{
Condições de trabalho de professores iniciantes de matemática: possibilidades e desafios no processo de desenvolvimento profissional
}

\author{
Francisco Jeovane do Nascimento ${ }^{1}$ \\ Ivoneide Pinheiro de Lima² \\ Eliziane Rocha Castro ${ }^{3}$ \\ Regiane Rodrigues Araújo ${ }^{4}$
}

\section{Resumo}

O estudo consiste em analisar as condições de trabalho dos professores de Matemática iniciantes, que vivenciaram a experiência do PIBID na formação inicial, e suas implicações no processo de desenvolvimento profissional dos mesmos. Optou-se pela pesquisa de cunho qualitativo, materializada através de um estudo de caso. Como instrumentos de coleta de dados utilizou-se a observação e a entrevista. Concluiu-se que as condições de trabalho propiciadas aos professores iniciantes não contribuem com um exercício qualificado da docência, representando um entrave ao desenvolvimento profissional. Ressalta-se, que embora as condições de trabalho sejam inadequadas, os jovens professores almejam a continuidade formativa.

Palavras-chave: Professores de matemática iniciantes; Condições de trabalho; Desenvolvimento profissional.

Working conditions of beginning teachers of mathematics: possibilities and challenges in the process of professional development

\begin{abstract}
The study consists of analyzing the working conditions of beginner mathematics teachers, who experienced the PIBID experience in initial training, and their implications in the process of professional development of the same. It was decided by qualitative research, materialized through a case study. As instruments of data collection, observation and interview were used. It was concluded that the working conditions offered to beginning teachers do not contribute to a qualified teaching exercise, representing an obstacle to professional development. It should be emphasized that although the working conditions are inadequate, the young teachers in which they strive for formative continuity.

Keywords: Beginner math teachers; Work conditions; Professional development.
\end{abstract}

\section{Introdução}

O presente estudo discorre sobre o desenvolvimento profissional de professores iniciantes de Matemática, no qual se analisou as condições de trabalho destes profissionais, em

\footnotetext{
${ }^{1}$ Universidade Estadual do Ceará e Secretaria da Educação Básica do Ceará (SEDUC-CE). Fortaleza/CE. Endereço eletrônico: jeonasc@hotmail.com

2 Universidade Estadual do Ceará. Fortaleza/CE. Endereço eletrônico: ivoneidepinhirodelima@gmail.com

${ }^{3}$ Universidade Estadual do Ceará. Fortaleza/CE. Endereço eletrônico: elizianecastro@hotmail.com

${ }^{4}$ Universidade Estadual do Ceará. Fortaleza/CE. Endereço eletrônico: regianearaujjo@hotmail.com
} 
virtude de os mesmos terem vivenciados experiências singulares no processo de formação inicial no âmbito do Programa Institucional de Bolsa de Iniciação à Docência (PIBID).

A iniciação profissional é um processo que se deve compreender no contexto escolar, local de desenvolvimento da atividade docente. Conforme Marcelo (2009), o docente aprende através da prática. É durante a prática que as dúvidas se evidenciam, exigindo a ressignificação e redirecionamento das ações pedagógicas. No processo de inserção profissional, denotado no contexto escolar, os professores vivenciam os problemas que circundam o seu contexto de trabalho, em que a formação inicial poderá subsidiá-lo, ou não, na resolução de situações múltiplas e divergentes que permeiam o dia a dia escolar.

Um dos grandes entraves ao desenvolvimento profissional de professores remete-se aos anos iniciais da carreira docente, apontados como os mais difíceis, face as lacunas oriundas da formação inicial, já que os estágios, que possuem finalidade de atrelamento entre o campo teórico e o prático, nem sempre atingem seus objetivos, gerando insegurança em aspectos essenciais da atuação educativa como, por exemplo, a questão disciplinar (SOCZEK, 2011).

O período inicial de exercício docente constitui-se numa fase importante de efetivação da identidade profissional, sendo fundamental para o delineamento de projetos relativos à melhoria pessoal e/ou profissional do professor e para a reflexão relativa à continuidade do trabalho, contribuindo no processo de desenvolvimento docente.

Nesse aspecto, a inserção no contexto de trabalho representa um momento de descobertas e de transição, em que os docentes elencam competências e habilidades que lhes permitirão (ou não) um bom desencadeamento da atividade profissional, prosseguindo o processo construtivo da identidade docente e repercutindo em seu desenvolvimento profissional. Wiebusch $(2014$, p.9) ressalta algumas fragilidades em relação ao exercício docente de professores iniciantes, como: "atitudes, sentimento de insegurança, timidez, dificuldade de aceitar o desinteresse dos alunos, compreender suas culturas e formas de agir que interferem no fazer pedagógico". Ressalta, ainda, a importância dos momentos de aprendizagem entre os pares, através da partilha de saberes com os profissionais mais experientes.

A formação precisa romper com modelos técnicos, sem nexos com a realidade em que os docentes estão inseridos e direcionar seus princípios de forma a auxiliar o docente em seu 
contexto educativo, desenvolvendo estratégias que possam conduzir o professor a realização de mudanças em suas práticas pedagógicas, passando a conviver com as dúvidas e incertezas provenientes das situações divergentes que perpassam o cotidiano educativo. Trata-se de formar o professor como um ser que necessita refletir sobre suas práticas e que busque, através da ação cotidiana, respostas aos seus questionamentos individuais e coletivos.

O período introdutório de ingresso como profissional docente é de grande relevância na aprendizagem do oficio inerente à profissão, em que o professor traz consigo experiências pessoais, acadêmicas e profissionais que perpassaram a sua trajetória de vida. Conforme Marcelo (2008, p.20) "Os primeiros anos de docência são fundamentais para assegurar um professorado motivado, implicado e comprometido com a sua profissão". Sobre esse aspecto, Tardif (2002, p.84) afirma que o período introdutório de iniciação a profissão "é muito importante na história profissional do professor, determinando, inclusive, seu futuro e sua relação com o trabalho".

O contexto escolar em que o professor atua exerce um papel importante no favorecimento (ou não) do processo de desenvolvimento profissional, remetendo ao incentivo das instituições escolares para que os docentes invistam em seu processo de formação ao longo da vida, valorizando a aprendizagem cooperativa e a troca de saberes, fomentando a pesquisa sobre a prática exercida, no intuito da revisão e redirecionamento de atitudes que contribuam em uma melhor sistematização dos conhecimentos.

$\mathrm{Na}$ perspectiva de um bom desenvolvimento da atividade docente e estímulo ao desenvolvimento profissional, Pimenta (2002) aponta a necessidade da indissociabilidade entre formação, condições de trabalho, infraestrutura escolar e carreira docente. Nesse aspecto, Libâneo (2011) expõe a ambivalência existente no contexto educativo atual, no qual se almeja a qualidade educacional sem a disponibilidade de condições efetivas para atingir tal finalidade, uma vez que as condições de trabalho da maioria dos docentes da educação pública, no nível básico, são precarizadas, em uma logística que busca apenas atender as necessidades dos governos neoliberais, cuja finalidade educativa remete a mera preparação para o mercado de trabalho, em oposição ao desenvolvimento do espirito crítico e questionador.

Nesses termos, emerge a relevância do processo de desenvolvimento profissional, a 
partir do qual Marcelo (2009) afirma que este objetiva subsidiar o professor no concebimento de mudanças relativas às suas concepções, em que o docente se sinta instigado a alterações nas suas práticas e saberes, de forma a repercutir positivamente na aprendizagem qualificada dos educandos.

A qualidade do desenvolvimento profissional é um fator relevante nas propostas de melhoria educativa, em que há o reconhecimento de que a escola não pode mudar se os professores e gestores também não mudarem. De forma geral, os professores buscam o desenvolvimento profissional na perspectiva de se tornarem melhores docentes, crescendo em aspectos profissionais e de satisfação pessoal, em que o fato de se tornarem melhores professores repercute no avanço dos índices de aprendizagem dos discentes (GUSKEY, 2002).

Com esteio nessas considerações, observa-se a relevância do desenvolvimento docente ao longo do exercício profissional, uma vez que esse processo objetiva proporcionar aos professores, conhecimentos que remetam as suas indagações individuais e coletivas, baseado no ambiente em que o educador exerce a sua atividade. Baptista $(2010$, p.46) afirma que "a escolha das estratégias que promovem o desenvolvimento profissional implica a clarificação dos objetivos a atingir, as concepções dos professores e as características do contexto".

O processo de desenvolvimento profissional docente remete a individualidade do professor, mas pode ser favorecido pelo contexto colaborativo. Ao fim da década de 90 , Ponte $(1998$, p. 10) afirmava que

\footnotetext{
Investir na profissão, agir de modo responsável, definir metas para o seu progresso, fazer balanços sobre o percurso realizado, reflectir com regularidade sobre a sua prática, não fugir às questões incómodas, mas enfrentá-las de frente (...). Estas atitudes podem ser mais ou menos favorecidas pelo contexto exterior, mas mesmo nas condições mais difíceis, estão sempre ao alcance de todo o professor.
}

Observa-se que o processo de desenvolvimento docente objetiva contribuir na melhoria de aspectos pessoais e profissionais do professor, de forma a repercutir na ação docente cotidiana, na perspectiva de uma melhor sistematização dos conhecimentos curriculares. Por outro lado, existem fatores que estimulam (ou não) o professor na busca pelo contínuo 
desenvolvimento profissional, em que as condições de trabalho se constituem como um desses elementos.

Na perspectiva de redirecionamento da formação inicial de professores, delineiam-se, no cenário educativo, políticas públicas que objetivam mudanças no processo formativo, uma vez que este processo esteja vinculado ao cotidiano docente e a vivências nas instituições escolares. Nessa premissa, enquadra-se o PIBID, que almeja a inserção dos licenciandos na escola, no período inicial da formação de forma a contribuir no conhecimento da complexidade que norteia a profissão, remetendo às necessidades docentes, proporcionando respostas aos questionamentos individuais e coletivos do futuro professor, contribuindo na identificação com a profissão (ou afastamento dela) e repercutindo no desenvolvimento profissional.

No desenvolvimento desta pesquisa, a atenção recaiu sobre egressos do PIBID, mais precisamente professores iniciantes de Matemática, que desenvolveram atividades inerentes às ações delineadas pelo subprojeto do curso de licenciatura em Matemática, no contexto da Universidade Estadual Vale do Acaraú (UVA) entre os anos de 2011 e 2014.

Essa escolha baseia-se no fato de um dos autores desta pesquisa ter integrado o quadro de bolsistas do PIBID no período compreendido entre os anos de 2010 e 2011, o que do ponto de vista ético poderia influenciar os dados do estudo, onde se optou por ações desenvolvidas posteriormente ao desligamento do autor das atividades propiciadas por essa experiência formativa singular.

A ideia central desse estudo consiste em analisar as condições de trabalho dos professores de Matemática iniciantes, que vivenciaram a experiência do PIBID na formação inicial, e suas implicações no processo de desenvolvimento profissional dos mesmos.

No delineamento da pesquisa, realizamos um estudo de caso com professores iniciantes de Matemática que vivenciaram experiências singulares no processo de formação inicial, no caso o PIBID. Como sujeitos participantes da pesquisa, utilizou-se uma amostra de 4 professores. 0 critério de escolha baseou-se no retorno relativo ao convite feito aos potenciais participantes, pois a coordenação do subprojeto do curso de licenciatura em Matemática/UVA disponibilizou o contato de todos os bolsistas que participaram do delineamento de atividades realizadas no âmbito do referido projeto. Realizou-se o convite aos licenciandos que ingressaram no PIBID nos 
anos de 2011 e 2012, recebendo-se o retorno de quatro ex-bolsistas, que atualmente exercem o oficio docente, dois ingressaram em 2011 e os outros dois em 2012.

\section{Desenvolvimento profissional de professores}

As questões relativas à profissionalização docente e suas repercussões no trabalho do professor ganham espaço no cenário educativo. Esta reflexão se originou a partir da conceituação de "desenvolvimento profissional", com a qual se desloca o centro de atenção do conteúdo do conhecimento a ser apropriado pelo professor para os processos de desenvolvimento do próprio professor (PONTE, 2014).

O desenvolvimento profissional constitui-se como um processo complexo, sendo importante que o educador se vislumbre como um ser em constante aprendizagem, na perspectiva de resolução de situações diversificadas que ocorrem no contexto escolar e no dia a dia da sala de aula (BAPTISTA, 2010).

No processo de desenvolvimento docente, os aspectos pessoais e profissionais do professor se integram em que “o professor é a pessoa e a pessoa é o professor. Que é impossível separar as dimensões pessoais e profissionais" (NÓVOA, 2009, p. 38). Dessa forma, os processos de formação inicial e continuada devem comprometer-se com o desenvolvimento docente como um todo, envolvendo o pessoal e o profissional e não de forma fragmentada.

O conceito de desenvolvimento profissional não foi oriundo de um processo rápido, mas pautado em estudos e pesquisas graduais. Estudos realizados por Abrantes e Ponte, em 1982, enfocavam a necessidade de formação contínua do professor de Matemática como fator importante no percurso referente ao desenvolvimento da atividade profissional, através da atualização de conhecimentos e da reflexão sobre a prática, buscando adequar-se as necessidades do ambiente que norteia a comunidade escolar.

Passadas algumas décadas, Ponte $(1995,2014)$ reorganizou seu conceito sobre desenvolvimento profissional, considerando-o como um processo de formação permanente no percurso de vida do professor, acontecendo em diversas fases e cenários da vida docente, envolvendo as experiências vivenciadas enquanto discente, perpassando a formação inicial no 
âmbito universitário, o ingresso como profissional da educação e continuando através das vivências formais e informais que circundam a atividade educativa ao longo do ofício profissional.

Pires e Martins (2010, p.415) afirmam que o desenvolvimento profissional é "Um processo que envolve todas as experiências espontâneas ou planificadas que são realizadas para benefício próprio ou do grupo ou da escola e que, consequentemente, vão contribuir para a melhoria das práticas em sala de aula".

Para Imbernón (2011) o desenvolvimento profissional é um conjunto de elementos que contribuem para que o docente tenha progressos em sua trajetória profissional, em que a melhoria das condições do princípio formativo, mesclada com outros fatores pertinentes favorece a melhoria do exercício docente, repercutindo na aprendizagem discente. Conforme Costa e Pavanello (2013) o desenvolvimento profissional de professores caracteriza-se como um processo constante de aprimoramento da atividade docente.

Compreende-se que o desenvolvimento profissional é um processo que almeja contribuir na melhora da atividade docente, perpassando a história de vida do professor, sua formação inicial, as condições sob as quais o mesmo exerce a sua atividade profissional, além das indagações pertinentes as questões pessoais e profissionais docentes. Esses fatores influenciam na ampliação dos conhecimentos relativos à profissão e questões práticas, além da ampliação de estratégias que tendem a subsidiar a melhoria do trabalho docente em sala de aula.

É preciso vislumbrar o processo de desenvolvimento profissional como algo além de modelos formativos, abrangendo também as questões ligadas aos aspectos que perpassam a profissão como, por exemplo, as condições de trabalho e as questões salariais, dentre outros.

O processo de desenvolvimento profissional origina-se mediante as inquietações e indagações do professor, em decorrência da necessidade de aprimoramento e adequação dos conhecimentos e práticas docentes ao contexto contemporâneo, não sendo imposto por programas de formação continuada destinados aos educadores, que não articulam saberes inerentes ao trabalho docente em sala de aula, mas partindo das inquietações individuais de cada educador, geralmente oriundas da formação inicial quando este se defronta com o contexto escolar e percebe os dilemas e dificuldades que envolvem a prática docente (LOPES, 2009).

O incentivo a autonomia e ao poder criativo/inovador docente, pautado pelo diálogo e 
pela criticidade, deve respaldar as instituições escolares, embora encontremos uma realidade diferente, no qual as questões referentes à produtividade educativa influenciam as instituições, regendo normas avaliativas que "prendem" o trabalho docente a determinados preceitos, não valorizando o pensamento autônomo dos professores, mas analisando a eficácia da instituição baseando-se no princípio da eficiência e produtividade (PIMENTA; ANASTASIOU, 2012).

A busca do desenvolvimento profissional deve levar em consideração os fatores culturais, sociais e individuais que circundam a realidade docente, concebendo o professor como um ser em constante aprendizagem e desenvolvimento. A melhora da práxis docente, baseada no aperfeiçoamento de estratégias pertinentes a efetivação da aprendizagem discente resulta do desenvolvimento profissional ao longo da prática, que deve ser marcada pelo apoio e incentivo das hierarquias superiores.

O professor desempenha sua atividade profissional em ambientes cada vez mais complexos, nos quais se depara com múltiplas situações em que deve tomar decisões, às vezes em momentos difíceis, além de desempenhar uma infinidade de tarefas e papéis, tendo que adequar seus métodos a realidade com a qual interage. Ponte (1994) destaca, ainda, que as escolas se deparavam com situações complexas, sujeitas ao controle do aparelho estatal, apresentando carências humanas e materiais, dificuldades proporcionadas pela diversidade de alunos com os quais precisam trabalhar.

Por outro lado, Matos (2009) afirma que passadas algumas décadas, observa-se que não houve avanços significativos nas concepções relativas à função docente, em que se vislumbra o professor como um ser contribuinte nas transformações sociais, mas em condições inadequadas para um bom exercício profissional, remetendo aos aspectos relacionados ao seu trabalho, formação pessoal e profissional, dentre outros fatores. Para a autora, é necessária a "valorização do professor como um profissional cheio de saberes que em sua experiência profissional constrói-se como um sujeito ativo, que ensina porque compreende o ensino, e aprende ao ensinar" (2009, p.33). De acordo com Ponte (2012, p.6),

O professor é visto com necessidades e potencialidades que importa descobrir, valorizar e ajudar a desenvolver. Neste processo de crescimento, marcado por uma evolução contínua eventualmente pontuada por momentos especiais, o 
protagonista principal é o professor, não os cursos ou as oportunidades que the são oferecidas.

Observa-se que a visibilidade relacionada às necessidades do professor apresentou, nas últimas décadas, poucas melhorias, em contradição com os preceitos designados pela sociedade, que questiona a escola como mola propulsora do desenvolvimento econômico e social. É relevante refletirmos sobre a forma como as instituições escolares encaram os aspectos relacionados às mudanças contemporâneas e de que forma as escolas podem proporcionar um desenvolvimento profissional adequado aos agentes que a compõem, baseado nos anseios e necessidades dos sujeitos envolvidos, pois "é através da identidade que nos percebemos, nos vemos e queremos que nos vejam" (MARCELO, 2009, p.112).

Valorizar o professor significa contribuir na compreensão dos contextos que norteiam a comunidade escolar, sejam eles históricos, sociais, culturais ou organizacionais, construindo elos entre o saber e o fazer. Significa vislumbrar o profissional como um ser dotado de saberes, oportunizando-Ihe espaços qualitativos de formação inicial e contínua, reconhecendo à docência como atividade intelectual, crítica e reflexiva. 0 desenvolvimento profissional deve ser visto como um processo contínuo e não como um evento ocasional (GUSKEY, 2002).

\section{Trajeto metodológico}

As abordagens e percursos teóricos escolhidos no decorrer de uma pesquisa devem pautar-se na busca de respostas que conduzam ao conhecimento do objeto de estudo investigado, no caso o desenvolvimento profissional de professores de Matemática iniciantes, partindo das inquietações, dúvidas e indagações iniciais, que vão surgindo ao longo da pesquisa. Como afirma André $(2008$, p.33) "A escolha de uma determinada forma de pesquisa depende antes de tudo da natureza do problema que se quer investigar e das questões específicas que estão sendo formuladas".

Nesses termos, optamos pela pesquisa de cunho qualitativo, visto que a presente investigação objetivou analisar o processo de desenvolvimento profissional de professores de Matemática iniciantes tomando como pressupostos as condições de trabalho propiciadas a estes 
profissionais em seu contexto de atuação.

Dessa forma, justifica-se a escolha pela abordagem qualitativa, uma vez que foram os sujeitos deste estudo - egressos do curso de licenciatura em Matemática que integraram o quadro de bolsistas do PIBID - e atuais professores da educação básica - que forneceram as respostas aos questionamentos propostos na realização da pesquisa.

Nos paradigmas de pesquisa qualitativa, optou-se pelo estudo de caso, visto que propicia desvelar a realidade vivenciada, averiguando-a de forma complexa e profunda, revelando a abundância de dimensões existentes num determinado problema ou situação. Como afirma Yin (2005, p.32): "um estudo de caso é uma investigação empírica que investiga um fenômeno contemporâneo dentro do seu contexto da vida real, especialmente quando os limites entre o fenômeno e o contexto não estão claramente definidos". Ressalta-se a relevância do estudo de caso na compreensão fenomenológica de determinado objeto investigado. Goldenberg (2004, p. 33) complementa esse pensamento, afirmando que

\footnotetext{
O estudo de caso reúne o maior número de informações detalhadas, por meio de diferentes técnicas de pesquisa, com o objetivo de apreender a totalidade de uma situação e descrever a complexidade de um caso concreto. Através de um mergulho profundo e exaustivo em um objeto delimitado, o estudo de caso possibilita a penetração na realidade social, não conseguida pela análise estatística.
}

O uso do estudo de caso como metodologia de pesquisa em Educação Matemática tem ganhado cada vez mais enfoque devido as suas características de projetar-se como uma averiguação que almeja descobrir o que há de mais relevante em um determinado caso particular.

Yin (2005) e Ponte (2006) enfatizam que uma particularidade do estudo de caso é o fato do mesmo tratar-se de uma investigação de cunho empírico, baseado na observação e na experiência, pautado pelo trabalho de campo, examinando um contexto específico a partir de múltiplos instrumentos de coleta de dados como, por exemplo, entrevistas e observações, de forma que contribuam na compreensão complexa do fenômeno em pauta.

Nesse estudo, foram utilizados como instrumentos de pesquisa a observação e 
entrevistas semiestruturadas individuais. A escolha por esses instrumentos baseia-se no fato de buscar, analisar e compreender os fenômenos relacionados às condições de trabalho dos sujeitos envolvidos e as repercussões de tal elemento no processo de desenvolvimento profissional dos mesmos.

Na pesquisa realizada, optou-se pela observação participante, pautada pelos estudos de Yin (2005) e Ludke e André (2013), haja vista afirmarem que a observação participante possui conexões com a entrevista e a análise documental, na perspectiva de consolidação dos resultados em pesquisas qualitativas, de forma especial no estudo de caso.

Nesta pesquisa foram realizadas quatro observações. Cada professor foi observado uma vez no contexto da sala de aula, com o intento de verificar em que condições os mesmos exercem a sua atividade profissional. As observações foram anotadas no caderno de campo, um instrumental utilizado para registros realizados nos momentos de observação e que possibilita uma posterior sistematização dos dados coletados (ABIB et al, 2013).

Os registros foram realizados nos meses de agosto e setembro de 2015, obedecendo à sequência em que ocorreram. Nesse momento, buscou-se relatar o que foi relevante ao objeto de estudo. Cada registro foi iniciado com a especificação da data, hora e duração de cada observação realizada.

$\mathrm{Na}$ proposta investigativa utilizamos a entrevista semiestruturada individual, que conforme Aires (2011, p.28) "consiste na interação entre entrevistador e entrevistado com base num conjunto de perguntas pré-estabelecidas". Complementando, Ludke e André (2013, p.40) afirmam que "a entrevista semiestruturada, que se desenrola a partir de um esquema básico, porém não aplicado rigidamente, permite que o entrevistador faça as necessárias adaptações". Nessa perspectiva, as respostas são escritas e/ou gravadas pelo pesquisador para uma posterior análise, baseadas nas indagações pertinentes a investigação proposta.

Com autorização prévia dos sujeitos investigados, as entrevistas foram realizadas nos meses de agosto e setembro de 2015 e gravadas para posterior descrição e análise do discurso, buscando fatores explícitos e implícitos que contribuíssem em respostas fidedignas aos questionamentos propostos na pesquisa.

Definiu-se a amostra da pesquisa com quatro professores, em decorrência da disposição 
voluntária dos mesmos em contribuir com o trabalho proposto, além do retorno em um tempo hábil e adequado, conforme o planejamento definido no decorrer do período em que se desenvolveu o projeto. Utilizou-se nomes fictícios para os sujeitos pesquisados: Hipátia, Sofia, Euclides e Arquimedes, garantindo o anonimato e sigilo em relação aos participantes do estudo, remetendo as questões éticas da pesquisa, de modo que sua participação na investigação não Ihe provoque nenhum dano imaterial.

Em relação aos sujeitos da pesquisa, dois são do sexo masculino e dois do sexo feminino. As professoras iniciantes ingressaram como bolsistas do PIBID em 2011 e os professores ingressaram em 2012.

A professora Hipátia tem 27 anos de idade e ao ingressar como acadêmica do curso de licenciatura em Matemática passou a exercer a docência como atividade profissional, fato ocorrido no ano de 2010; foi bolsista do PIBID entre os anos de 2011 e 2013, concluindo o curso superior em 2014. A professora Sofia tem 23 anos de idade e atua como docente desde $o$ ano de 2014; foi bolsista do PIBID entre os anos de 2011 e 2013, tendo concluído o curso de licenciatura em Matemática no início de 2014. O professor Euclides tem 23 anos de idade e exerce à docência desde 2014, integrou o quadro de bolsistas do PIBID entre os anos de 2012 e 2013, concluindo o curso de licenciatura em Matemática no início de 2014. O professor Arquimedes tem 25 anos de idade e atua como professor desde o ano de 2014, ano em que concluiu o curso de licenciatura em Matemática; foi bolsista do PIBID entre os anos de 2012 e 2013.

Enfatiza-se que os sujeitos participaram da pesquisa de forma voluntária, assinando um Termo de Consentimento Livre e Esclarecido, como forma de proteção legal e moral dos envolvidos na pesquisa. Foram fornecidas informações relativas à pesquisa, de modo que os sujeitos compreendessem a natureza do processo investigativo e os impactos do mesmo sobre eles.

Esses sujeitos desenvolviam sua atividade docente, no momento da pesquisa empírica, em três cidades distintas localizadas na região norte do estado do Ceará. O local de trabalho dos sujeitos não será revelado, em virtude de uma das cidades possuir uma única escola de ensino médio e, por conseguinte, a citação desta instituição poderia conduzir a identificação do professor participante da pesquisa, embora o núcleo gestor de cada escola tenha assinado a 
Carta de Solicitação para Realização de Pesquisa na Instituição Escolar.

Os sujeitos da pesquisa foram imprescindíveis durante todo o processo do estudo, possibilitando diferentes formas de elaboração e construção dos conhecimentos apresentados, compreendendo os princípios que orientam a investigação, possibilitando reflexões acerca das questões que problematizam e norteiam esta investigação.

\section{Inserção profissional: condições de trabalho dos professores iniciantes de matemática}

Inicialmente, convém destacar que a rede estadual de ensino do Ceará obedece a Lei no 11.738 de 16/07/2008, no que tange a jornada de trabalho docente e assim, os professores efetivamente, dedicam $1 / 3$ da carga horária as questões referentes à preparação de aulas e materiais didáticos dentre outras atividades, sendo esta ação, dentro do contexto escolar, denominada de hora-atividade.

A professora Hipátia tinha uma jornada de 20 horas semanais, lecionando no período vespertino. Seu trabalho estava distribuído da seguinte maneira: 16 horas de jornada didática, ou seja, de trabalho exercido em sala de aula e 4 horas de hora-atividade, ou seja, dedicadas ao planejamento.

A docente considera que as condições de trabalhos disponibilizadas para o exercício profissional não são adequadas. Desse modo, elenca alguns fatores que prejudicam o bom desempenho dos professores, a começar pelas salas de aula que são muito quentes, em virtude da infraestrutura não proporcionar uma boa ventilação. Há que se considerar que a professora exerce sua docência na região semiárida nordestina, caracterizada por altas temperaturas.

Outro fator é a falta de companheirismo, ou seja, apoio dos outros professores, que trabalham de forma individualizada, citando também a coordenação da instituição, que não dialoga e nem ouve as sugestões dos professores. Nesse sentido Hipátia afirma:

O coordenador, inclusive eu tive alguns embates com ele (...) e eu acho que a contribuição dele como coordenador não é das melhores, eu acho que é uma pessoa que não tem a mente aberta para estar na função, pois não escuta a opinião dos docentes da escola, que poderiam contribuir em ações que melhorassem nosso trabalho e contribuíssem na aprendizagem dos alunos.

Periódico Horizontes - USF - Itatiba, SP-Brasil - e019005 
A fala da professora expõe a falta de diálogo na instituição escolar em que atua. Verificase, portanto, que esse fator representa uma dificuldade para o exercício efetivo da profissão, pois o diálogo entre a equipe de suporte pedagógico (gestor e coordenador) e professores é importante para o planejamento e organização das atividades no âmbito escolar.

O diálogo é imprescindível no contexto escolar, visto que cada professor traz consigo experiências pessoais, acadêmicas e profissionais que perpassaram a sua trajetória formativa e de vida e que deveriam ser aproveitadas pela escola na perspectiva de utilizar as vivências, a criatividade e os saberes destes atores escolares na busca do aprimoramento da atividade educacional e do desenvolvimento profissional.

Hipátia não especificou quanto tempo se dedica ao planejamento, estudos e pesquisa, mas destacou que "Eu estudo a parte, um estudo mais para mim, um estudo pessoal, que possa contribuir muito para mim e dessa maneira eu possa contribuir, levar alguma coisa para os alunos".

Ela explicitou também que procura fazer todas as atividades relativas ao ofício docente no ambiente escolar e que em seu domicílio dedica-se mais aos estudos pessoais, que Ihe permitam ampliar seu repertório de conhecimentos. A professora destaca que o tempo dedicado à jornada extraclasse deveria ter, também, formações, de modo que auxiliassem o docente no contexto escolar. Destaca, ainda, que as condições de trabalho desfavoráveis Ihe estimularam a buscar outro curso de nível superior, no caso o de Economia.

A fala da professora evidenciou as condições desfavoráveis que permeiam o seu trabalho docente, de modo que a mesma não se sentia estimulada nesse oficio, fator que prejudica o seu desenvolvimento profissional. Destacou, ainda, a necessidade de formação continuada, que representa um fator contribuinte no processo de desenvolvimento profissional. Dessa forma, a escola pode ser utilizada como lócus privilegiado de formação, através do estudo e da reflexão dos dilemas e questionamentos que perpassam o contexto escolar, valorizando os saberes docentes e a experiência de cada indivíduo que integra a escola.

Em relação aos principais desafios vivenciados na carreira docente, a professora Hipátia destacou que:

Periódico Horizontes - USF - Itatiba, SP-Brasil - e019005 
As dificuldades é enquanto gestão de escola, eu acho que depende muito da escola ter uma abertura para novas ideias ou não, tem escolas que não são abertas para isso, querem dar aquele jeitinho porque precisam conseguir aquele resultado, tem que ser aquele resultado, então você acaba ficando naquela mesmice. O principal desafio é esse dilema de que o resultado é o mais importante e não a aprendizagem dos alunos.

Por meio da fala da professora, reitera-se a falta de diálogo no contexto escolar onde a mesma está inserida, pois esta não participa das decisões que afetam o trabalho docente de forma coletiva, haja vista o fato de a mesma citar, ainda, a gestão escolar que se preocupa mais com os resultados das avaliações de larga escola, do que com o processo de aprendizagem dos estudantes, pressionando os docentes a trabalharem uma rotina que muitas vezes não remete as necessidades da turma, não estimulando a autonomia dos professores.

Considera-se que o processo de desenvolvimento profissional docente denota o incentivo da gestão escolar, proporcionando aos professores a participação democrática em decisões que perpassam o contexto de trabalho, a partir do qual se evoca a autonomia relativa ao delineamento de estratégias que possam reverberar na melhoria da aprendizagem dos educandos, mediante as necessidades individuais e coletivas dos estudantes e não com a imposição de modelos prontos, distanciados da realidade cotidiana docente/discente (IMBERNÓN, 2011).

É notória a preocupação da professora com o aprendizado dos alunos e com a formação pessoal e coletiva, fatores imprescindíveis ao desenvolvimento profissional, embora se delineie em condições contraditórias, dentre estas contradições, as exigências impostas aos professores em seu cotidiano escolar, como por exemplo, projetos que são designados pelos órgãos governamentais sem nenhuma discussão com a gestão e professores das escolas.

Nos momentos de observação, verificou-se que a docente buscava o estabelecimento de um clima harmonioso na sala de aula. Dentre suas atividades, realizou predição oral acerca do conteúdo explorado, aguçando o interesse dos indivíduos; em seguida, explicou o assunto e destinou um tempo para questionamentos e inferências discentes, em uma relação de diálogo mútuo e estímulo aos educandos em participarem da construção do seu próprio conhecimento.

Tal fator se constitui como uma ação contribuinte no desenvolvimento profissional dos 
professores, pois este considera a opinião dos alunos com os quais interage, objetivando melhorias concernentes ao seu trabalho (BAPTISTA, 2010).

A professora Sofia lecionava dois dias na semana, com uma carga horária de 6 (seis) aulas semanais em sala de aula e 2 (duas) horas de hora-atividade dedicadas ao planejamento.

Sofia afirmou que as condições de trabalho não são adequadas, não havendo na instituição a disponibilidade de materiais que auxiliem os docentes no desenvolvimento de estratégias de ensino. Outro fator que a educadora citou como empecilho ao seu desempenho profissional foi o fato da mesma lecionar no turno noturno em uma unidade de extensão da escola, localizada na zona rural. A professora destacou que

(...) muitas vezes não tem o recurso, nem o apoio necessário pelo fato de lecionar no anexo da escola (...). Essa semana, por exemplo, eu não tinha quadro para dar aula e eu tive que mudar totalmente meu plano para poder conseguir dar minha aula e dar uma aula de física sem quadro, como é que a gente faz? Então o professor tem que ter mais de um plano para ativar os alunos na hora da aula, porque senão você fica sem dar aula. Sem contar que é no turno noturno, que já é uma forma diferente de lecionar, porque temos um tempo menor de aula, aí se torna um desafio maior.

As condições de trabalho adversas, enfrentadas pela jovem professora, se constitui como um desafio ao exercício e desenvolvimento profissional. Nessa perspectiva, salienta-se que o contexto escolar em que o professor atua exerce um papel importante no favorecimento do processo de desenvolvimento profissional, remetendo as questões referentes à infraestrutura escolar e a disponibilidade de materiais necessários a um exercício qualificado da docência, para que o professor possa se utilizar de uma gama variada de estratégias que repercutam na aprendizagem dos estudantes.

A docente afirmou que sempre estudava em casa, revisando conteúdos curriculares que leciona ou preparando lista de exercícios acerca de assuntos que serão abordados em seu contexto profissional. Sofia expõe que "Eu tenho o planejamento na escola, mas como só ensino dois dias na semana, eu sempre olho alguma coisa diferenciada para levar para os alunos, reviso alguns conteúdos, preparo lista de exercícios".

A fala de Sofia revelou a importância da busca pela atualização do repertório de 
estratégias docentes, pautada nas necessidades dos educandos e no contexto com o qual interage, reverberando em uma aula mais qualificada e que proporciona a compreensão e efetivação dos conteúdos curriculares sistematizados, incentivando o professor a aprender continuamente, desenvolvendo-se no âmbito pessoal e/ou profissional (PONTE, 2012).

No âmbito da pesquisa, Sofia evidenciou que almejava o ingresso em um curso de mestrado na área da Educação Matemática. A necessidade formativa da professora surge como uma consequência da busca pelo aperfeiçoamento profissional, mediante as experiências e situações diversificadas com as quais a docente se defronta em seu cotidiano de trabalho, na perspectiva de atualização profissional e realização pessoal. Essa motivação da professora é interessante, visto que a busca por uma melhor qualificação repercute em seu desenvolvimento profissional, emergindo das necessidades e desafios individuais e coletivos da professora, respeitando o seu ritmo e interesse próprio (MARCELO, 2009).

Como principal desafio, a professora Sofia citou o desenvolvimento de estratégias de ensino que incentivem os discentes a continuidade dos estudos, afirmando que boa parte dos educandos com os quais interage são desmotivados, pretendem concluir o ensino médio e ingressar no mercado de trabalho sem dar continuidade aos estudos.

Mesmo em condições desfavoráveis, a docente tem esperanças de que com estratégias que despertem o interesse dos alunos esse quadro mude. Nesse sentido, a professora Sofia explicitou que:

O desafio maior é buscar estratégias que consigam chamar a atenção dos alunos e fazer com que os alunos tenham perspectivas de vida, porque muitos alunos não têm, aí se torna mais difícil a gente querer ensinar ou até mostrar um caminho do aprender se esse aluno não tem perspectiva de vida, de crescer, de querer algo maior (...) mas a gente tentando pode ser que fiquem as sementes para que eles possam ter perspectivas de poderem ir atrás do sonho deles, de querer ter um futuro melhor (...).

A preocupação da professora revelou que a função docente não remete apenas a sistematização de conhecimentos, mas que é imprescindível olhar para as necessidades e interesses dos alunos, de forma que eles se sintam estimulados a ampliarem e buscarem novas possibilidades de crescimento pessoal e profissional. Afinal, por intermédio de suas práticas, 
saberes e experiências e mediante o delineamento de ações individuais e coletivas, os professores exercem um importante papel na busca de mudanças referentes ao contexto educacional em que atuam, originando reflexões pertinentes que encaminham as necessidades sobre o trabalho docente, que necessitam ser valorizadas e colocadas em prática, pelo intermédio da ressignificação da profissão (PIMENTA; ANASTASIOU, 2012).

Observando a aula da professora Sofia, percebeu-se que a mesma buscava estabelecer um clima favorável a aprendizagem curricular, embora enfrentasse o desafio de lecionar para educandos do turno noturno, que exercem jornada de trabalho durante o dia, chegando à escola visivelmente cansados. Mesmo com esta adversidade, a docente motivava os alunos a participarem da aula, relacionando o conteúdo com exemplos do cotidiano, realizando questionamentos sobre o assunto explorado e estimulando os estudantes a tirarem as possíveis dúvidas provenientes do conteúdo trabalhado.

É imprescindível que o professor perceba a importância do desenvolvimento de ações adequadas a realidade dos educandos com os quais interage. Para isso, faz-se necessário, que os conteúdos não se constituam apenas como um emaranhado de ideias presentes em livros didáticos, mas que sejam adequados e contextualizados objetivando a evidência da relação dialógica entre teoria e prática, almejando a utilização do conhecimento como instrumento de interpretação da realidade (NASCIMENTO, 2016).

O professor Euclides realizava uma jornada de trabalho semanal de 20 horas, sendo 16 em sala de aula e 4 horas dedicadas ao planejamento.

O docente afirmou que as condições de trabalho não são adequadas, citando como um dos fatores a associação entre a infraestrutura da escola em que lecionava na época da pesquisa e a temperatura elevada da região. Nesse sentido, o professor destacou que as salas não são ventiladas, acarretando prejuízos aos alunos e aos professores, que reclamam desse aspecto negativo. Outro fator que Euclides evidenciou foi a superlotação das salas de aula, que impossibilitava a realização de uma ação individual mais efetiva. O professor Euclides afirmou que:

(...) O fato de enfrentarmos salas bem numerosas inviabiliza desenvolver uma boa aula com os alunos, a gente tem sala bem numerosa, com média de 45 alunos por sala, a gente deveria ter um limite para conseguirmos estabelecer Periódico Horizontes - USF - Itatiba, SP-Brasil - e019005 
um pouco mais de qualificação, já que aqui em (cidade da região norte do estado do Ceará) a gente nota que tem uma cobrança em relação a índices de aprendizagem. Acho que um número de alunos viável para todas séries o rendimento seria bem melhor.

A fala do professor revelou uma situação preocupante, visto que a escola tem a função de transformação social, mas as condições que são ofertadas dificultam a realização de tal finalidade, a superlotação das salas de aula inviabiliza um trabalho com mais qualidade.

Durante a observação das aulas de Euclides, constatou-se que a turma era composta por 45 alunos. Concorda-se com Euclides, que essa quantidade dificulta a realização de uma ação mais efetiva para a aprendizagem curricular e por isso não contribui para o desenvolvimento profissional docente.

A visibilidade educativa como um fator de promoção e inclusão social é eminente, permeando debates em todos os níveis das esferas político/social, embora seja um processo contraditório, torna-se necessário a efetivação prática dos discursos educacionais, proporcionando aos professores condições de trabalho adequadas as necessidades do contexto com o qual interagem (PIMENTA; ANASTASIOU, 2012).

Euclides afirmou que dispõe de pouco tempo para se dedicar a estudos pessoais, em virtude de sempre levar atividades extras para realizar em seu domicílio, expondo que:

Fora do contexto escolar, tenho pouco tempo para estudos pessoais, porque além de ser profissional eu também sou chefe de família. É necessário dispor tempo para a familia da gente. Infelizmente, sempre levo coisas do trabalho para fazer em casa, porque não consigo resolver tudo na escola, tipo atividades para elaborar, trabalhos e provas para corrigir, pesquisar atividades para os alunos.

O professor evidencia as múltiplas funções que exerce em seu contexto pessoal e profissional, afirmando que tais fatores limitam seus momentos de estudo, pois no contexto pessoal precisa dedicar um tempo à família e no contexto profissional há o fato de suas turmas serem numerosas e por essa razão, sempre leva atividades do trabalho para casa, exigindo uma constante reorganização na sua vida em ambas as situações.

Como principal entrave ao seu exercício profissional cotidiano, o docente citou a 
indisciplina, em virtude da grande quantidade de alunos em sala, afirmando que "A minha maior dificuldade acho que é a indisciplina e o desinteresse de alguns alunos, porque esses fatores comprometem o rendimento deles".

As questões relativas à indisciplina e o desinteresse dos alunos são fatores que desestimulam os docentes em sua ação cotidiana, visto que foi observado que há momentos que comprometem o andamento da aula, no qual o professor tem que parar a ação em execução no decurso do tempo pedagógico para chamar a atenção de determinados alunos, comprometendo a concentração dos demais estudantes.

Pela experiência como professor da educação básica, acrescenta-se à fala de Euclides, o fato da família preocupar-se mais com a sobrevivência cotidiana do que com fatores que incentivam os filhos a buscarem outros aportes em sua formação escolar e pessoal mediante a continuidade dos estudos em algum curso superior ou a frequência em um curso profissionalizante, dentre outros exemplos.

O professor Arquimedes perfaz uma jornada semanal de 40 horas, lecionando 27 horas semanais e o restante do tempo, 13 horas, são dedicados a jornada de hora-atividade, dentro da própria escola, conforme assegurado pela Lei $n \cong 011.738$ de 16/07/2008

O docente considerou que sua carga horária atrapalhava um pouco o seu desempenho como profissional da educação, afirmando também que a instituição escolar em que lecionava na época da pesquisa não apresentava condições satisfatórias para um planejamento adequado em virtude do espaço físico reduzido. O educador afirmou que:

O espaço da escola não é muito legal para a gente estar se organizando, a gente tem que sempre tá correndo de um lado pro outro, atrás de materiais e a gente não consegue deixar todos os materiais da gente lá, a gente não consegue tranquilidade, a escola não tem um espaço propício para estarmos nos planejando.

Arquimedes evidenciou que a estrutura física da escola era inadequada, fator que é prejudicial a sua ação docente, podendo desestimular o professor no desenvolvimento de estratégias diferenciadas de ensino. Essa situação é preocupante, visto que é necessário que a escola propicie uma estrutura física em que o professor tenha condições de desenvolver um 
trabalho compatível com as mudanças educacionais almejadas pelos organismos governamentais.

Observando a aula do professor, percebeu-se que o mesmo explorou a predição oral dos conteúdos, relacionando o assunto explorado com situações cotidianas inerentes ao contexto que circunda os indivíduos. Explicou o tópico trabalhado, abrindo espaço para questionamentos e inferências, considerando o erro algo comum e importante para reorganização de ideias e do pensamento lógico, vislumbrando possibilidades de efetivação da aprendizagem.

Partindo do observado nas aulas de Arquimedes, destaca-se que o delineamento de estratégias didático-pedagógicas diversificadas deve ser um elemento vislumbrado pelo professor em seu cotidiano de trabalho, objetivando despertar e aguçar o interesse dos educandos, visto que a mera exposição oral não representa um indicativo de uma aula pautada pelo aspecto qualitativo. Nesses termos, emerge a relevância do processo de desenvolvimento profissional docente, almejando a contínua busca formativa e troca de conhecimentos com os pares, na premência de melhorias que reverberem em aspectos pessoais e/ou relativas ao trabalho cotidiano (NASCIMENTO, 2016).

Arquimedes relatou, também, que os recursos disponíveis na escola não contribuem no desenvolvimento de estratégias de ensino que exploram o poder criativo dos estudantes, citando como exemplo o laboratório de informática da escola:

(...)A gente quer, por exemplo, fazer uma aula usando computadores, geralmente os computadores além de possuírem sistema operacional Linux, no qual ninguém sabe manusear, ainda só prestam dez aparelhos, onde em uma sala com 35 alunos fica difícil, aí não tem como fazer aula diferenciada.

As tecnologias que foram trabalhadas no contexto do PIBID destacaram-se como elementos contribuinte no seu repertório de conhecimentos, mas que no campo de atuação profissional possui limitações de uso, em decorrência da insuficiência de equipamentos e do desconhecimento do sistema operacional utilizado, restringindo o uso de estratégias vivenciadas enquanto bolsista de iniciação à docência.

Embora tenhamos conseguido consensos importantes no âmbito educativo, como, por exemplo, a instituição do piso salarial nacional e as questões relativas à carga horária dedicada Periódico Horizontes - USF - Itatiba, SP-Brasil - e019005 
ao planejamento, ainda se faz necessário o avanço nos debates e na luta por melhorias na atividade docente, visto que o reconhecimento da educação como fator de inserção e promoção social não tem acompanhado a melhoria das condições de trabalho destinadas aos professores em seu exercício profissional.

No que concerne à relação com os outros professores, Arquimedes afirmou que havia entre eles um clima de ajuda mútua e aprendizagem colaborativa, uma vez que os professores trocavam práticas e saberes. Esse aspecto é importante para o desenvolvimento profissional do professor, visto que a troca de saberes possibilita o olhar para o outro, incorporando elementos que contribuam na ação docente, em um processo dialético em que ensino e aprendo (PONTE, 2012). Mediante as experiências vivenciadas, cada professor vai construindo a sua identidade docente, mantendo características que o tornam único, singular (NÓVOA, 2009).

Faz-se necessário vislumbrar os professores como sujeitos e não objetos da ação profissional, cujos direcionamentos devem orientar-se no incentivo a autonomia docente, na perspectiva de que os próprios professores proponham soluções para os problemas práticos que circundam o seu contexto de trabalho, passando de um conhecimento espontâneo para ações concretas (IMBERNÓN, 2011).

Em relação aos estudos pessoais, Euclides afirmou que:

O tempo que tenho para estudar é mais na parte da noite, estudar o que acho interessante para mim, não para lecionar. Para lecionar eu dedico um tempo do meu planejamento na escola, porque tenho algumas aulas livres, então pego o material de trabalho e dou uma olhada. Em casa, às vezes vejo a questão relativa a algum exercício que vou levar para os alunos.

Portanto, o professor possuía uma rotina de estudos e procurava adquirir conhecimentos, tanto individual como referentes as atividades escolares. Afirmou ainda que almejava o ingresso em um curso de mestrado profissionalizante na área de Matemática, no sentido de buscar melhorias nos âmbitos pessoal e profissional, pois acredita que este fator contribuirá em sua prática docente, ampliando seu repertório de conhecimentos profissionais.

Como principal desafio ao seu exercício profissional cotidiano, o professor Arquimedes citou as dificuldades de aprendizagem dos estudantes em relação ao delineamento de conteúdos 
matemáticos, afirmando que:

A maior dificuldade que a gente encontra em sala de aula, não só para os professores de Matemática é a questão relativa ao aprendizado do aluno, que por mais que a gente queira fazer uma atividade diferenciada, há muita dificuldade em conseguir assimilar o conteúdo teórico para que a gente possa levar para a prática. Boa parte dos alunos tem dificuldades em conhecimentos básicos da Matemática e não era para ser assim.

O desenvolvimento de estratégias de ensino que relacionam os conhecimentos escolares com as vivências sociais cotidianas propicia a superação do paradigma que permeia o ensino de Matemática: o fato cultural de a disciplina ser vista como algo estático e pronto (LOPES, 2009). A fala do professor revelou que ele buscava levar para a sala de aula ações que contribuem na superação desse paradigma, atrelando os conhecimentos teóricos com a sua exemplificação prática.

\section{Considerações finais}

Considerando os dados obtidos nesta pesquisa, percebe-se nas falas dos sujeitos investigados que, de maneira geral, as condições de trabalho propiciadas aos professores iniciantes não contribuem com um exercício qualificado da docência, sendo um processo antagônico através o qual se denota a escola e aos docentes a função de transformação social, mas em uma conjuntura que não contribui com tal pressuposto.

Frente a essa realidade, destaca-se que a sociedade contemporânea designa a escola múltiplas funções, dentre elas a de desenvolver sujeitos que tenham condições de promoção contínua da sua aprendizagem, embora o que se observa é a perda da autonomia. Além disso, o trabalho do professor é sujeito a análises externas, tendo como referência a padronização de conhecimentos curriculares, sem levar em consideração às condições de trabalho docente, as questões salariais, a jornada de trabalho, entre outros aspectos que influenciam no exercício e desenvolvimento profissional.

Foi verificado que os professores destinavam uma parte do seu tempo para estudos 
pessoais e profissionais, conforme a realidade de cada um. Esse aspecto é importante, pois acredita-se que os estudos consistem em um dos caminhos para a postura do professor de Matemática em sala de aula, visto que sua formação inicial foi impregnada por conhecimentos prontos e acabados, com poucas discussões sobre os aspectos pedagógicos.

Os sujeitos enfocaram algumas experiências que vivenciaram no contexto do PIBID e que ainda se fazem presente no cotidiano de trabalho, como por exemplo, a importância da aprendizagem colaborativa, o desenvolvimento de estratégias didático/pedagógicas que remetem as necessidades dos educandos, a reflexão sobre a prática e a busca pela atualização profissional.

O conjunto das experiências variadas que Hipátia, Sofia, Euclides e Arquimedes vivenciaram no contexto do PIBID e exercitam na sua prática docente têm contribuído no processo de desenvolvimento profissional de cada educador, embora de forma muito contida, visto que são professores em início de carreira. Afinal, o desenvolvimento profissional docente não ocorre de forma isolada, mas incorporado a muitos fatores inseridos num contexto de relações complexas integradas ao espaço escolar e social.

Considera-se que o processo de desenvolvimento profissional pode cooperar numa melhor qualificação do professor, respeitando seus anseios, crenças e necessidades e que isso implique numa melhoria dos saberes específicos, didáticos e pedagógicos docentes, repercutindo no aperfeiçoamento do trabalho docente e na aprendizagem curricular qualificada dos educandos.

Destaca-se que o PIBID propiciou aos sujeitos momentos de formação, constituição e aperfeiçoamento da aprendizagem da profissão, repercutindo no seu repertório de conhecimentos profissionais e na sua prática docente, consolidando novos aportes para a formação de professores, demonstrando que a atividade docente não se restringe as dimensões da sala de aula, já que as relações oriundas do espaço educativo são múltiplas e abrangentes, envolvendo aspectos culturais, sociais, história de vida dos professores e alunos, entre outros, que permeiam a comunidade escolar. Nessa concepção, a participação como bolsista do programa se evidenciou como um fator que estimula o processo de desenvolvimento profissional dos professores iniciantes.

Periódico Horizontes - USF - Itatiba, SP-Brasil - e019005 
A utilização da observação e da entrevista como procedimentos de coleta de dados revelou as dificuldades e desafios que os professores iniciantes enfrentavam em seu cotidiano profissional. As escolas não ofereciam condições propícias a um bom desenvolvimento do exercício educativo, perpassando a estrutura física e material, além da falta de apoio da gestão escolar que não concede autonomia aos docentes.

Nessa perspectiva, observou-se que esses entraves nas condições de trabalho não vêm favorecendo, de forma mais consistente, o processo de desenvolvimento profissional docente. Esse fato é lamentável, visto que o desenvolvimento profissional deve emergir das aspirações docentes, mas as instituições escolares devem propiciar condições de estudo e trabalho que incitem os professores a buscarem desenvolver-se profissionalmente, na perspectiva de melhoria da qualidade do trabalho docente, repercutindo na aprendizagem dos educandos.

Em remate, ressalta-se que embora as condições de trabalho sejam inadequadas, os jovens professores possuem uma rotina de estudo, em que buscam conhecimentos pessoais e profissionais, almejando a continuidade formativa. Esse fator é significativo, visto que a formação é um processo contínuo, que não se inicia e nem termina na universidade, mas que acompanha o docente por toda a vida, em um constante desenvolvimento profissional.

\section{Referências}

ABIB, G. et al. Observação participante em estudos de administração da informação no Brasil. RAE-Revista de Administração de Empresas, v.53, n.6, p. 604-616, nov./dez. 2013.

ABRANTES, P.; PONTE, J. P. Professores de matemática. que formação? Ensino da matemática: Anos 80. In: Actas do colóquio realizado no âmbito do encontro internacional de homenagem a José Sebastião e Silva. Lisboa: SPM, p.269-292, 1982.

AIRES, L. Paradigma qualitativo e práticas de investigação educacional. E-book. Lisboa: Universidade Aberta, 2011. Disponível em: https://repositorioaberto.uab.pt/handle/10400.2/ 2028. Acesso em: 30 ago. 2016.

ANDRÉ, M. E. D. A. Estudo de caso em pesquisa e avaliação educacional. 3. ed. Brasília: Liber Livro editora, 2008.

BAPTISTA, M. L. M. Concepção e implementação de actividades de investigação: um estudo 
com professores de física e química do ensino básico. 2010. 586 f. Tese (Doutorado) Universidade de Lisboa, Lisboa, 2010.

BRASIL. Lei $N^{\circ} 11.378$, de 16 de julho de 2008. Institui o piso salarial nacional para os profissionais do magistério público da educação básica. Diário Oficial da União: Brasília, 2008.

COSTA, J. R.; PAVANELLO, R. M. O desenvolvimento profissional docente: um processo contínuo de aperfeiçoamento de professores. In: VI Congresso Internacional de Ensino da Matemática, 2013, Canoas. Anais [...] Canoas, ULBRA, out. 2013. p. 1-12. Disponível em: http://www.conferencias.ulbra.br/index.php/ciem/vi/paper/viewFile/591/518. Acesso em 23 ago. 2016.

GOLDENBERG, M. A arte de pesquisar: como fazer pesquisa qualitativa em Ciências Sociais. 8. ed. Rio de Janeiro: Record, 2004.

GUSKEY, T. R. Professional development and teacher change. Teachers and teaching: theory and practice. v.8, n.3/4, p.381-391, 2002. Disponível em: physics.gmu.edu/ hgeller/Teacher Workshop/Guskey2002.pdf. Acesso em: 23 nov. 2014.

IMBERNON, F. Formação docente e profissional: formar-se para a mudança e a incerteza. Trad. S. C. Leite. 9. ed. São Paulo, SP: Cortez, 2011.

LIBÂNEO, J. C. Adeus professor, adeus professora? novas exigências educacionais e profissão docente. 13. ed. São Paulo: Cortez, 2011.

LOPES, A. R. L. V. Aprendizagem da docência em matemática: o clube da matemática como espaço de formação inicial de professores. 1. ed. Passo Fundo: Editora Universidade de Passo Fundo, 2009.

LUDKE, M.; ANDRÉ, M. E. D. A. Pesquisa em educação: abordagens qualitativas. 2. ed. Rio de Janeiro: E.P.U. Editora, 2013.

MARCELO, C. (Org.). El professorado principiante: inserción de la docência. 1. ed. Barcelona: Ediciones Octaedro, 2008.

MARCELO, C. A identidade docente: constantes e desafios. Revista Brasileira de Pesquisa sobre Formação Docente, v.01, n.01, p.109-131, ago./dez. 2009.

MATOS, M. G. Desenvolvimento profissional de professores que ensinam Matemática: como professor se transforma no profissional que é?. 2009. 132 f. Dissertação (Mestrado) Universidade Federal do Pará, Belém, 2009.

NASCIMENTO, F. J. do. Professores iniciantes de matemática: um estudo sobre seu 
desenvolvimento profissional. 2016. 135 f. Dissertação (Mestrado) - Universidade Estadual do Ceará, Fortaleza, 2016.

NÓVOA, A. Professores - Imagens do futuro presente. 1. ed. Lisboa: Educa, 2009.

PIMENTA, S. G. Pedagogia e pedagogos: caminhos e perspectivas. 1. ed. São Paulo: Cortez, 2002.

PIMENTA, S. G.; ANASTASIOU, L. G. C. Docência no ensino superior. 4. ed. São Paulo: Cortez editora, 2012.

PIRES, M. V.; MARTINS, C. Formação e desenvolvimento profissional do professor de Matemática. In: GOMES, H.; MENEZES, L.; CABRITA, I. (Orgs.), Actas do XXI Seminário de Investigação em Educação Matemática. Lisboa: APM, 2010, p.414-424.

PONTE, J. P. O desenvolvimento profissional do professor de matemática. Revista Educação e Matemática, n.31, p.9-20, jul./set. 1994.

PONTE, J. P. Perspectivas de desenvolvimento profissional de professores de matemática. In: PONTE, J. P. et al (Orgs.). Desenvolvimento profissional de professores de matemática: que formação?. 1. ed. Lisboa: SEM-SPCE, 1995, p.193-211.

PONTE, J. P. Da formação ao desenvolvimento profissional. Actas do ProfMat 98. Lisboa: APM, 1998, p.27-44. Disponível em: http://www.educ.fc.ul.pt/docentes/jponte/docs-pt/98Ponte(Profmat).doc. Acesso em: 15 ago. 2016.

PONTE, J. P. Estudos de caso em educação matemática. Bolema, v.19, n.25, p.62-69, ago./dez. 2006.

PONTE, J. P. Estudando o conhecimento e o desenvolvimento profissional do professor de matemática. In: PLANAS, N. (Coord.). Teoria, crítica y prática de la educación matemática. 1. ed. GRAO: Barcelona, 2012, p. 83-98.

PONTE, J. P. Formação do professor de matemática: perspectivas atuais. In: PONTE, J. P. (Org.). Práticas profissionais dos professores de matemática. 1. ed. Instituto de Educação da Universidade de Lisboa: Lisboa, 2014, p.343-358.

SOCZEK, D. PIBID como formação de professores: reflexões e considerações preliminares. Revista Brasileira de Pesquisa sobre Formação de Professores, v.03, n.05, ago./dez. 2011.

TARDIF, M. Saberes docentes e formação profissional. 2. ed. Petrópolis: Vozes, 2002.

WIEBUSCH, E. M. Desenvolvimento profissional de professores iniciantes: desafios e 
possibilidades na educação profissional e tecnológica. In: X ANPED SUL, 2014, Florianópolis. Anais [...] Florianópolis, out. 2014, p.1-17. Disponível em: http://xanpedsul.faed.udesc.br/arq_ pdf/488-0.pdf. Acesso em: 28 set. 2014.

YIN, R. K. Estudo de caso: planejamento e métodos. 3. ed. Trad. D. Grassi, Porto Alegre: Bookman, 2005.

Recebido em fevereiro de 2018.

Aprovado em outubro de 2018. 